\title{
1 Towards definitions of critical illness and critical care using concept analysis
}

2 Raphael Kazidule Kayambankadzanja ${ }^{1,2}$, Carl Otto Schell ${ }^{3,4,5}$, Martin Gerdin Wärnberg ${ }^{3,6}$,

3 Thomas Tamras $^{7}$, Hedi Mollazadegan ${ }^{8}$, Mats Holmberg ${ }^{9,10,11}$, Helle Mølsted Alvesson ${ }^{3}$, Tim

4 Baker $^{3,12,13}$

5 1. Department of Anaesthesia and Intensive Care, Queen Elizabeth Central Hospital, Blantyre Malawi

6 2. Department of Public Health, Kamuzu University of Health Sciences

$7 \quad 3 . \quad$ Department of Global Public Health, Karolinska Institutet, Stockholm, Sweden

8 4. Centre for Clinical Research Sörmland, Uppsala University, Eskilstuna, Sweden

9 5. Department of Medicine, Nyköping Hospital, Nyköping, Sweden.

6. Function Perioperative Medicine and Intensive Care, Karolinska University Hospital, Solna, Sweden

7. Södertälje Hospital, Stockholm, Sweden

8. The Department of Addiction Medicine, Sankt Goran Hospital, Stockholm, Swede

9. Faculty of Health and Life Sciences, Linnaeus University, Växjö, Sweden

10. School of Health, Care and Social Welfare, Mälardalen University, Eskilstuna, Sweden

11. Centre for Clinical Research Sörmland, Uppsala University, Eskilstuna, Sweden

12. Department of Clinical Research, London School of Hygiene \& Tropical Medicine, London, UK

13. Department of Emergency Medicine, Muhimbili University of Health and Allied Sciences, Dar es Salaam, Tanzania

\section{Abstract}

Objective

As "critical illness" and "critical care" lack consensus definitions, this study aims to explore how the concepts' are used, describe their defining attributes and propose potential definitions.

\section{Design}

24 We used the Walker and Avant stepwise approach to concept analysis. The uses and definitions of the concepts were identified through a scoping review of the literature and an online survey of 114 global clinical experts. Through content analysis of the data we extracted codes, categories and themes to determine the concepts' defining attributes and we proposed potential definitions. To assist understanding, we present model, related and contrary cases concerning the concepts, we identified antecedents and consequences to the concepts, and defined empirical referents.

\section{Results}

The defining attributes of critical illness were a high risk of imminent death; vital organ dysfunction; requirement for care to avoid death; and potential reversibility. The defining attributes of critical care were the identification, monitoring and treatment of critical illness; vital 
organ support; initial and sustained care; any care of critical illness; and specialized human and physical resources. Our proposed definition of critical illness is, "a state of ill health with vital organ dysfunction, a high risk of imminent death if care is not provided and the potential for reversibility". Our proposed definition of critical care is, "the identification, monitoring and treatment of patients with critical illness through the initial and sustained support of vital organ functions."

\section{Conclusion}

The concepts critical illness and critical care lack consensus definitions and have varied uses.

Through concept analysis of uses and definitions in the literature and among experts we have identified the defining attributes of the concepts and propose definitions that could aid clinical practice, research, and policy making.

\section{Strengths and Limitations of the Study}

- This concept analysis is the first study to systematically describe the uses and definitions of the concepts critical illness and critical care

- The study uses a scoping review of the literature and input from over one hundred clinical experts from diverse settings globally to identify the defining attributes and provide proposed definitions of the concepts

- Some uses and definitions of the concepts in languages other than English, in unpublished grey literature and from clinical experts not included in the study may have been missed

- As current usage of the concepts is diverse, the proposed definitions may not be universally accepted and are aimed to stimulate further discussion

\section{Introduction}

9 The concepts critical illness and critical care are commonly used in healthcare. In PubMed, both are Medical Subject Headings (MeSH) terms, and searches for "critical illness" or "critical care" return 40,000 and 220,000 articles respectively. While it may seem evident that the concepts 
concern patients with very serious illness and their care, there is a lack of consensus around their precise definitions.

This causes problems for clinical practice, research, and policy making. For the clinician, discordant interpretations of when a patient is critically ill can lead to differing clinical assessments and treatments despite similar states: when should a patient be regarded as critically ill so that an alarm should be triggered and when is admission to an intensive care unit warranted? For the researcher, it can be difficult to design a study or interpret findings: studying the effect of a treatment for critical illness requires clear eligibility criteria and translating the findings to another patient group requires that the groups have similar clinical conditions. For the policy maker, prioritising programmes and investments designed to improve care for very sick patients relies on comparisons between similar groups and clearly defined interventions.

Even quantifying the total global burden of critical illness has been challenging due to the lack of an agreed definition. Proxies have been used instead, for example summing up syndromes considered to comprise critical illness such as sepsis and acute lung injury- resulting in estimates of up to 45 million critical illness cases each year.(1) Low- and middle-income countries are suspected to have the highest burden (2), but the lack of a definition has hampered comparisons across settings.

Studying the care for critically ill patients has also been problematic. Studies have focused on care provided in hospital locations such as in intensive care or emergency units, which exclude care provided in hospitals lacking such units, and to critically ill patients in general hospital wards. (3-5) In the COVID-19 pandemic, there have been great efforts to describe, scale-up and improve care for critically ill patients throughout the world $(3,5)$ and a lack of agreement around critical care has hampered these efforts.

These examples illustrate how important concepts are as the building blocks of theories and communication. Ideally, concepts are clearly defined and their use well described for unambiguous communication and an understanding about exactly what is being described or explained. (6) Concept analysis is a method for investigating how concepts are used and understood. Concept analyses have been conducted in diverse fields such as in teamwork (7), postoperative recovery(8) and bioterrorism preparedness(9), all with the aim of providing basic conceptual understanding and facilitating communication. In this paper, we have used 
92 concept analysis, following the stepwise approach described by Walker and Avant(6). The first

93 two steps in the approach are to choose the concept and determine the aim of the analysis. Our 94 chosen concepts are critical illness and critical care and our aims are to explore the uses and

95 definitions of the concepts in published sources and by global clinical experts, leading to a 96 description of the defining attributes of the concepts and to proposed definitions.

\section{Methods}

98 The Walker \& Avant approach to concept analysis uses the following steps: identifying the uses 99 of the concept; determining the concept's defining attributes; presenting a model case, 100 identifying related and contrary cases; identifying antecedents and consequences; and defining empirical referents.(6)

\section{Identifying the uses of the concept}

103 We identified the uses of the concepts of critical illness and critical care through a scoping review of the literature and a web-based survey of global experts.

105

106

107

108

109

110

111

112

\section{Critical Illness}

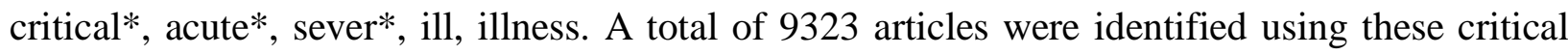
searching. Of these, 1126 articles were identified as duplicates and the remaining 8199 articles were screened by title and abstract review by two of the authors (TT and HM). 8168 articles were excluded as they did not concern critical illness, were not written in English or were not available in full text online, leaving 31 articles for inclusion for full-text review. In the full-text 
review, 22 articles were excluded as they did not define critical illness, and so nine articles were included in the analysis (Supplementary Table 1).

\section{Critical Care}

The search terms used were terminolog*, etymolog*, nomenclatur*, definition*, plus critical care, intensive care, emergency care, acute care. A total of 7286 articles were identified using these critical care terms in the databases and an additional six articles were identified through hand-searching. Of these, 1964 were identified as duplicates and the remaining 5322 articles were screened by title and abstract review by two of the authors (TT and HM). 5269 articles were excluded as they were not concerning critical illness, not written in English or not available in full text online, leaving 59 articles for inclusion for full-text review. In the full-text review, 46 articles were excluded as they did not define critical care and so 13 articles were included in the analysis (Supplementary Table 2).

\section{Expert survey}

The survey used open-ended questions to gather information about the experts' definitions of critical illness and critical care, and how they see the relationship of the concepts to connected concepts in order to provide context. The survey included the questions: i. How would you define critical illness?, ii. How would you define critical care?, iii. Do critical care and intensive care differ? If yes, in what way? iv. Do critical care and emergency care differ and if yes, in what way? v. Do critical care and acute care differ and if yes, in what way?

The inclusion criterion for an expert to be invited to participate in the survey was experience in any medical specialty that includes care of patients with acute, severe illness. Experts were identified from a stakeholder mapping of global critical care done by one of the authors (TB, unpublished), and those known to the researchers to be global experts in the field of critical care. Purposive sampling was used to invite experts with the aim of including 100 experts with a balance between specialties, geographical locations, health worker cadres and gender. In total 146 experts were invited to take part, and 113 completed the survey (77\% response rate) (Table $1)$.

\section{Table 1: Characteristics of the experts who participated in the survey}

\begin{tabular}{|l|l|}
\hline Variable & Frequency (\%) \\
\hline
\end{tabular}




\begin{tabular}{|l|l|}
\hline All & 114 \\
\hline Gender & \\
Male & $80(70.2)$ \\
Female & $34(29.8)$ \\
\hline Continent & \\
Africa & $42(36.8)$ \\
Europe & $29(25.4)$ \\
North America & $26(22.8)$ \\
Asia & $12(10.5)$ \\
South America & $3(2.6)$ \\
Australia & $2(1.8)$ \\
\hline Cadres* & \\
Physician & $93(53.1)$ \\
Researcher & $62(35.4)$ \\
Nurse & $12(6.9)$ \\
Policy Maker & $5(2.9)$ \\
Other & $3(1.7)$ \\
\hline Specialty* & \\
Anaesthesia/Intensive Care & $75(59.1)$ \\
Emergency Care & $20(15.8)$ \\
Medicine & $12(9.5)$ \\
Paediatrics & $7(5.5)$ \\
Surgery & $6(4.7)$ \\
Obstetrics and Gynaecology & $2(1.6)$ \\
Other & $5(3.9)$ \\
\hline Asthe experts were asked to select all that app
\end{tabular}

* As the experts were asked to select all that apply, the sum may exceed $100 \%$

150 The definitions of critical illness and critical care from the scoping reviews and the expert survey were charted and analysed using a content analysis based on methods developed by Erlingsson \& Brysiewicz.(12) First, the data from any parts of the literature and from the expert survey that concerned the uses or definitions of the concepts were extracted. The data were coded and the codes analysed iteratively by the study team. Redundant codes were removed and similar codes were arranged into categories. The data were revisited when new categories arose or when diverse opinions with contrasting attributes were identified. Through the process, themes emerged that captured the defining attributes of the concepts. Using the defining attributes, definitions of the concepts were constructed by the research team to be coherent and useful.

Presenting a model case, related and contrary cases, identifying antecedents and consequences, and defining empirical referents

162 The model cases, related, and contrary cases were developed by the researchers to provide 
analysis. Model cases were developed to be clinically realistic and to include all the defining attributes. Related cases were developed that include some, but not all, of the defining attributes, and contrary cases that are clearly "not the concept", containing none of the defining attributes. For simplicity in this study, we limited our cases to examples of patients with respiratory disease. Antecedents and consequences were identified as events that occur prior to the occurrence of each concept and as the outcomes of each concept respectively. Empirical referents were identified as phenomena that demonstrate the occurrence of each concept "in real life".

Ethical considerations: Informed consent was provided by all of the experts. The Research Ethics Committee of the London School of Hygiene and Tropical Medicine approved the study (Reference number 22661).

\section{Results}

The results relate to steps 4-8 in the Walker and Avant approach, as steps 1-3 have been described in the introduction and methods.

\section{Critical Illness}

\section{Defining attributes}

A total of 48 codes were identified from the uses and definitions of critical illness from the scoping review and expert survey. The codes were analysed into 14 categories and 4 themes. (Table 2). The themes represent the defining attributes of critical illness: high risk of imminent death; vital organ dysfunction; requirement for care to avoid death; and potential reversibility. (Figure 1)

\section{Table 2. Content analysis for the concept critical illness}

\begin{tabular}{|c|c|c|}
\hline Code & Category & Theme \\
\hline Severe illness & \multirow{2}{*}{ Severe illness } & \multirow{9}{*}{$\begin{array}{l}\text { High risk of } \\
\text { imminent death }\end{array}$} \\
\hline Process of increasing severity & & \\
\hline Imminent risk of death & \multirow{4}{*}{$\begin{array}{l}\text { High risk of imminent } \\
\text { death }\end{array}$} & \\
\hline Enough severity to lead to death rapidly & & \\
\hline Can kill within a short time & & \\
\hline Medical condition that results in short term mortality & & \\
\hline Sudden onset illness or acute deterioration & \multirow{3}{*}{$\begin{array}{l}\text { Acute onset or } \\
\text { deterioration }\end{array}$} & \\
\hline Acute life-threatening illness & & \\
\hline An episode of acute illness & & \\
\hline
\end{tabular}


medRxiv preprint doi: https://doi.org/10.1101/2022.01.09.22268917; this version posted January 10, 2022. The copyright holder for this preprint (which was not certified by peer review) is the author/funder, who has granted medRxiv a license to display the preprint in perpetuity.

It is made available under a CC-BY-NC-ND 4.0 International license .

\begin{tabular}{|c|c|c|}
\hline Increased risk of death & \multirow{5}{*}{ Life-threatening } & \\
\hline Continuous threat to life and well-being & & \\
\hline Life-threatening or potentially life-threatening disease & & \\
\hline High probability of life-threatening deterioration & & \\
\hline Acutely life-threatening injury or illness & & \\
\hline At least one and often multiple organ dysfunction & \multirow{4}{*}{$\begin{array}{l}\text { Organ dysfunction or } \\
\text { failure }\end{array}$} & \multirow{10}{*}{$\begin{array}{l}\text { Vital organ } \\
\text { dysfunction }\end{array}$} \\
\hline Failure in one or more organ systems that needs support & & \\
\hline Hemodynamic instability, respiratory failure, seizure, disorders of consciousness & & \\
\hline Diseases with vital organ failures as complications & & \\
\hline Threatened organ failure & \multirow{3}{*}{$\begin{array}{l}\text { Threatened organ } \\
\text { dysfunction }\end{array}$} & \\
\hline Potential disturbances of vital organ functions & & \\
\hline Threatened end-organ damage & & \\
\hline Deranged vital parameters & \multirow{3}{*}{$\begin{array}{l}\text { Vital signs derange- } \\
\text { ments }\end{array}$} & \\
\hline Physiologic reserve is diminished, as manifested by abnormal vital signs & & \\
\hline NEWS2 $\geq 7$ & & \\
\hline Associated with significant morbidities if untreated & \multirow{6}{*}{$\begin{array}{l}\text { Treatment needed to } \\
\text { avoid death }\end{array}$} & \multirow{19}{*}{$\begin{array}{l}\text { Requirement for } \\
\text { care to avoid } \\
\text { death }\end{array}$} \\
\hline Decline in a patient's ability to survive on their own & & \\
\hline Conditions requiring rapid intervention to avert death or disability & & \\
\hline An illness which without rapid treatment would result in death or disability. & & \\
\hline Needs prompt and sustained intervention to avert death or lifelong disability & & \\
\hline If no intervention is made, death is certain & & \\
\hline Requiring minute-by-minute nursing and/or medical care & \multirow{6}{*}{$\begin{array}{l}\text { Requirement for } \\
\text { immediate treatment }\end{array}$} & \\
\hline Requires a rapid diagnosis and response to ensure good outcomes & & \\
\hline Illnesses where timely care can reduce the chances of death and disability & & \\
\hline Requires immediate intervention & & \\
\hline The illness needs close monitoring and prompt management & & \\
\hline Treatment delays of hours or less make interventions less effective & & \\
\hline Requiring organ support & \multirow{3}{*}{$\begin{array}{l}\text { Requirement for } \\
\text { organ support }\end{array}$} & \\
\hline Requiring vital organ support & & \\
\hline Requiring intensified patient monitoring and organ support & & \\
\hline Critical care services & \multirow[t]{2}{*}{ Requires critical care } & \\
\hline ICU admission & & \\
\hline Illness that results in need for more than standard of care & \multirow{2}{*}{ Need for specific care } & \\
\hline Acute disease that needs specific treatment alongside the disease itself & & \\
\hline Some element of treatability & \multirow{2}{*}{$\begin{array}{l}\text { Reversible with } \\
\text { treatment }\end{array}$} & \multirow{5}{*}{$\begin{array}{l}\text { Potential } \\
\text { reversibility }\end{array}$} \\
\hline Any treatable life-threatening reversible illness & & \\
\hline Reversible life-threatening organ failure & \multirow{3}{*}{ Potentially reversible } & \\
\hline Life-threatening situation, illness or disease that is potentially reversible & & \\
\hline Acute potentially reversible illness & & \\
\hline
\end{tabular}

186

\section{Figure 1: The defining attributes of critical illness}




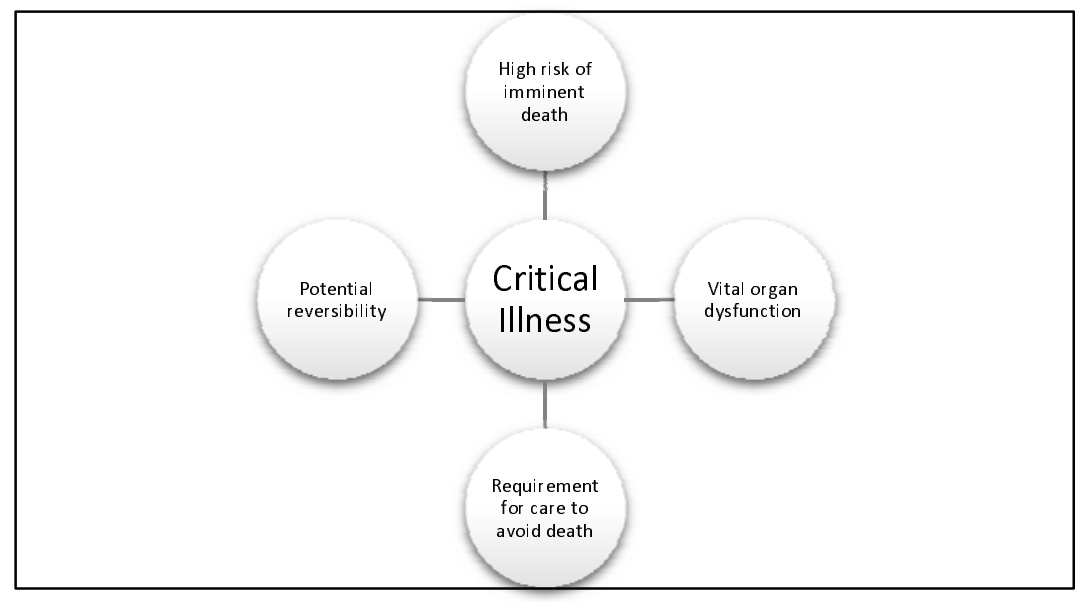

Proposed operational definition

190

191

192

193

194

195

196

197

198

199

200

201

202

203

204

205

206

207

208

The proposed definition for critical illness is "Critical illness is a state of ill health with vital organ dysfunction, a high risk of imminent death if care is not provided and the potential for reversibility."

\section{Cases}

\section{A model case of critical illness (a case including all the defining attributes)}

A woman has a viral pneumonia. She is breathless and hypoxic with a low oxygen level in her blood (oxygen saturation) of $74 \%$. Her lungs are dysfunctional, and she has a life-threatening condition that is likely to lead to her death in the next few hours. She requires care to support her lungs (oxygen therapy) and if she receives that care, she has a chance of recovery.

A related case for critical illness (a case including some of the defining attributes but not the attribute of "imminently life-threatening")

A man has a chest infection. He has a fever, is coughing up green sputum and feels short-ofbreath when walking. He has an oxygen saturation of $91 \%$. He has a serious condition, but it is not imminently life-threatening. He requires treatment, likely with antibiotics, but it is uncertain whether he requires any organ support such as oxygen. His condition is potentially reversible, and he can recover.

\section{A contrary case for critical illness (a clear example of "not the concept")}

A woman has lung cancer. She is coughing up small amounts of blood but is able to walk to the hospital. She has an oxygen saturation of $94 \%$. She is sick and she requires treatment. However, 
medRxiv preprint doi: https://doi.org/10.1101/2022.01.09.22268917; this version posted January 10, 2022. The copyright holder for this preprint (which was not certified by peer review) is the author/funder, who has granted medRxiv a license to display the preprint in perpetuity.

It is made available under a CC-BY-NC-ND 4.0 International license .

209

210

211

212

213

214

215

216

217

218

219

220

221

222

223

224

225

226

227

228

229

230

231

her illness is not imminently life-threatening, she has no dysfunctional vital organ and she does not require immediate care. Her condition may or may not be reversible.

\section{Antecedents and consequences of Critical Illness}

The antecedents of critical illness are the onset of illness, in mild or moderate form, with progressing severity. The consequences of critical illness are either recovery or death.

\section{Empirical Referents}

There are an estimated 30-45 million cases of critical illness globally each year(1). Many patients are cared for in hospitals with illnesses that are causing vital organ dysfunction and that are imminently life-threatening. There is much work done to identify patients with critical illness such as the use of single severely deranged vital signs(13), or compound scoring systems such as the National Early Warning Score (NEWS) and The Sequential Organ Failure Assessment score (SOFA) (14,15) . In hospitals, the severity of patients' conditions can be assessed using tools such as the Acute Physiology and Chronic Health Evaluation (APACHE) (16) and the Simplified Acute Physiology Score (SAPS)(17).

\section{Critical Care}

\section{Defining attributes}

A total of 60 codes were identified from the definitions of critical care from the scoping review and expert survey. The codes were analysed into 13 categories and 5 themes. (Table 3) The themes represent the concept's defining attributes: identification, monitoring and treatment of critical illness; vital organ support; initial and sustained care; any care of critical illness; and specialized human and physical resources. (Figure 2)

\section{Table 3: Content analysis for the concept critical care}

\begin{tabular}{|c|c|c|}
\hline Codes & Category & Theme \\
\hline Identifying and addressing critical illness & \multirow{3}{*}{$\begin{array}{l}\text { Identification and } \\
\text { monitoring of critical } \\
\text { illness }\end{array}$} & \multirow{8}{*}{$\begin{array}{l}\text { Identification, } \\
\text { monitoring and } \\
\text { treatment of critica } \\
\text { illness }\end{array}$} \\
\hline Medical care with timely monitoring & & \\
\hline Appropriate monitoring of critical illness & & \\
\hline Management of critically ill patients & \multirow{5}{*}{$\begin{array}{l}\text { Treatment of critical } \\
\text { illness }\end{array}$} & \\
\hline Treat critical illness & & \\
\hline Care given to the critically ill & & \\
\hline Services required to stabilize critical illness & & \\
\hline Reduce the risk of death from a critical illness & & \\
\hline
\end{tabular}




\begin{tabular}{|c|c|c|}
\hline Care dedicated to patients with severe illness or potentially severe condition & & \\
\hline Managing life-threatening condition & \multirow{4}{*}{$\begin{array}{l}\text { Addressing life- } \\
\text { threatening condition }\end{array}$} & \\
\hline Preventing the occurrence of life-threatening conditions & & \\
\hline Treatment and management due to the threat of imminent deterioration & & \\
\hline Medical care required to reduce the risk to the patient's life & & \\
\hline Care to sustain cardiopulmonary functions & \multirow{5}{*}{$\begin{array}{l}\text { Supporting vital } \\
\text { functions }\end{array}$} & \multirow{10}{*}{ Vital organ support } \\
\hline Support the patient's hemodynamic or cardiorespiratory status & & \\
\hline $\begin{array}{l}\text { Supportive care in critical illness to enable body's systems to continue } \\
\text { functioning before definitive treatment can work }\end{array}$ & & \\
\hline Care of vital organ failure & & \\
\hline Focus of care on supporting vital organs until improvement & & \\
\hline Providing organ support & \multirow{5}{*}{ Organ support } & \\
\hline Main focus on organ-supporting treatment. & & \\
\hline Support of vital organ function, or reverse specific organ dysfunctions & & \\
\hline Supportive care for organs that are failing & & \\
\hline Provision of support to dysfunctional body systems & & \\
\hline Early management for saving and maintaining life & \multirow{2}{*}{ Timely care } & \multirow{8}{*}{ Initial and sustained care } \\
\hline Rapid and timely intervention that is administered in critical illness & & \\
\hline From admission until the course of illness ends, either in full recovery or death & \multirow{4}{*}{$\begin{array}{l}\text { From start of critical } \\
\text { illness until the } \\
\text { patient is no longer } \\
\text { critically ill }\end{array}$} & \\
\hline From home through to discharge from hospital & & \\
\hline From the time of first contact with healthcare services through to stabilization & & \\
\hline To the point where the illness or injury is no longer acutely life-threatening & & \\
\hline Critical care could be over days to weeks & \multirow[t]{2}{*}{ Sustained care } & \\
\hline Constant monitoring & & \\
\hline Irrespective of the location of the patient within the health system & \multirow[t]{2}{*}{ Any location } & \multirow{4}{*}{$\begin{array}{l}\text { Any care of critical } \\
\text { illness }\end{array}$} \\
\hline Anywhere in the emergency or inpatient setting & & \\
\hline Any care provided to critically ill patients & \multirow{2}{*}{$\begin{array}{l}\text { Any care provided to } \\
\text { critically ill patients }\end{array}$} & \\
\hline Can be specialized care but depends on the level of resources & & \\
\hline Usually located in an area with infrastructure to support these activities & \multirow{5}{*}{ Specific area } & \multirow{14}{*}{$\begin{array}{l}\text { Specialized human and } \\
\text { physical resources }\end{array}$} \\
\hline Inside a healthcare facility, outside the emergency department & & \\
\hline High dependency care & & \\
\hline Care in ICU or Critical care unit & & \\
\hline $\begin{array}{l}\text { A place where equipment, staff and environment is ready to save patients with } \\
\text { life-threatening disease }\end{array}$ & & \\
\hline Multidisciplinary care & \multirow{4}{*}{$\begin{array}{l}\text { Multi-disciplinary and } \\
\text { specialist staff }\end{array}$} & \\
\hline Specially trained staff & & \\
\hline Essentially a team-based and multi-professional care & & \\
\hline Requires the grouping of special facilities and specially trained staff & & \\
\hline Higher level of care than is available on a general ward & \multirow{5}{*}{ High-intensity care } & \\
\hline Minute-by-minute nursing and/or medical care & & \\
\hline Advanced respiratory support / mechanical ventilation & & \\
\hline Nursing $24 / 7$ & & \\
\hline High nurse: patient ratio no lower than 1:2 & & \\
\hline
\end{tabular}

232

\section{Figure 2: The defining attributes of critical care}




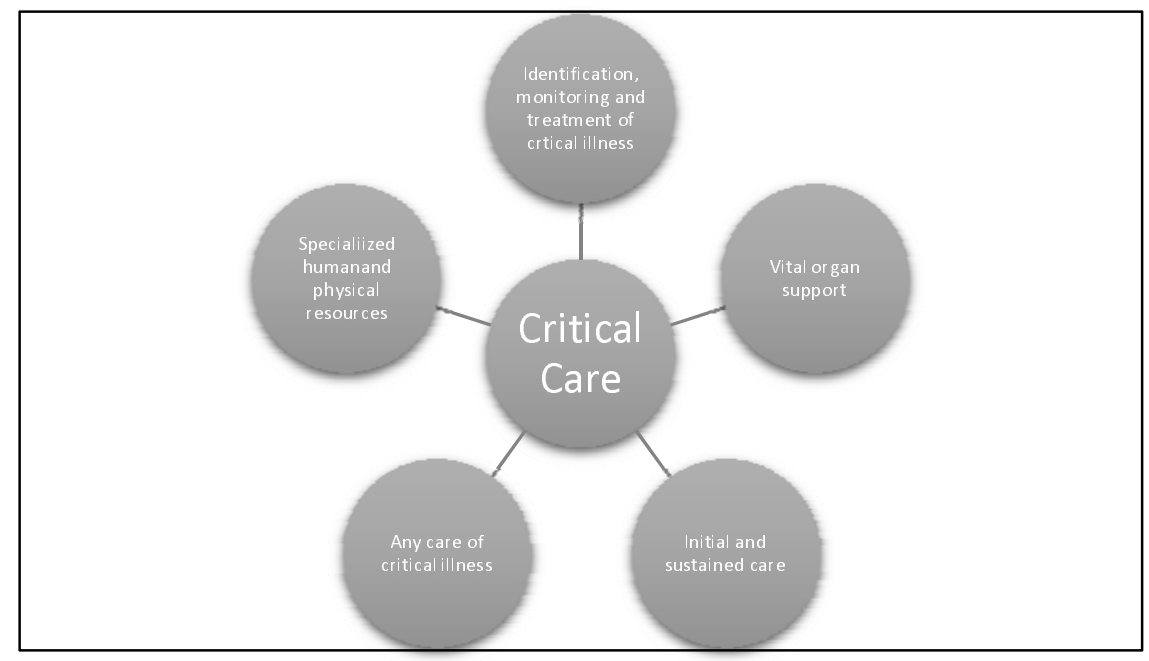

\section{Proposed operational definition of Critical care}

\section{A model case of critical care (a case including all the defining attributes)}

A woman with a viral pneumonia is rapidly identified as critically ill when she arrives at the hospital. She is immediately admitted to a unit with supplies for managing critically ill patients and treatment is started. Nurses and doctors who have been trained in the care of critical illness monitor her regularly, and provide continuous care, titrating the treatments as needed. Continuous oxygen therapy is provided for her life-threatening hypoxia, supporting her respiratory dysfunction, until she has recovered and is no longer critically ill.

\section{A related case of critical care (a case including some of the defining attributes but not the}

\section{attribute of "vital organ support")}

Care in a hospital is provided to a man with a chest infection. A nurse assesses him at arrival to hospital. A doctor admits him to the ward, prescribes antibiotics and decides he is not critically ill and does not require support for any of his vital organs. After four days the doctor discharges him from hospital.

A contrary case of critical care (a clear example of "not the concept") 
medRxiv preprint doi: https://doi.org/10.1101/2022.01.09.22268917; this version posted January 10, 2022. The copyright holder for this preprint (which was not certified by peer review) is the author/funder, who has granted medRxiv a license to display the preprint in perpetuity.

It is made available under a CC-BY-NC-ND 4.0 International license .

254 In the outpatient department, care is provided to a woman with lung cancer. A doctor and a nurse

255 do some investigations and prescribe some medications. She is sent home with a follow-up

256 appointment two weeks later.

\section{Antecedents and consequences of critical care}

258 The antecedents of critical care are the contact of the patient with the healthcare system and may 259 include other care of a patient who has not deteriorated to the point of becoming critically ill.

260 The consequences of critical care are either the patient's recovery or death.

\section{Empirical Referents}

262 Many hospitals have wards or units for the provision of critical care, such as Emergency Units, 263 High Dependency Units or Intensive Care Units (ICUs) (18). Critical care can also be provided 264 in general wards, and a recent global consensus specified the care that should be included for all 265 patients with critical illness in any hospital location (19). Rapid Response Teams or Medical 266 Emergency Teams have been introduced into some hospitals, often consisting of staff from the 267 ICU responding to calls from the wards when a critically ill patient has been identified, and 268 providing either critical care on the ward, or transferring the patient to the ICU (20).

\section{Discussion}

271

We have described how the concepts critical illness and critical care are used and defined in the literature and by global experts using a concept analysis approach.

273 Our proposed definition for critical illness of, " $a$ state of ill health with vital organ dysfunction, a high risk of imminent death if care is not provided and the potential for reversibility", is similar to those in some key publications. Chandrashekar et al state that, "Critical illness is any condition requiring support of failing vital organ systems without which survival would not be 277 possible" (21) . Painter et al write that, "A critically ill or injured patient is defined as one who 278 has an illness or injury impairing one or more vital organ systems such that there is a high probability of imminent or life-threatening deterioration in the patient's condition"(22) Indeed, we found widespread agreement in the literature and expert sources that critical illness concerns life-threatening illness with organ dysfunction. 
282 However, we found diverse and varied usage of the concept concerning the attribute of 283 reversibility and the interface between critical illness and the natural process of dying. Some uses 284 included only illness that was potentially reversible - these sources regarded that for critical 285 illness there should be a possible chance of recovery. Without this, critical illness would be a 286 concept that encompasses the dying process - everyone would be critically ill immediately 287 before death - which would conflict with many clinical uses and understandings of the term., 288 Others had a wider interpretation including all life-threatening illness and did not include reversibility in the definition as it is difficult to identify in the clinical setting, and the concept risks becoming context dependent, (high-resource interventions may reverse some critical illness which would not be possible in low-resource healthcare). Our iterative content analysis method led to our interpretation that reversibility should be included as one of the defining attributes, and this conclusion should be seen as one possible interpretation that can stimulate further discussion.

295 It is hoped that the proposed definition of critical illness assists communication in the field.

296 Previously, studies about critical illness have focused on patients in certain hospital units, or with 297 diseases or syndromes as proxies for critical illness that exclude some critically ill patients.(1) 298 Our definition of critical illness is not diagnosis or syndrome specific and can be due to any underlying condition. The definition could facilitate the specification of clinical criteria for the identification of critical illness, estimates of the overall burden of critical illness, assessments of outcomes for patients with critical illness across centres and settings, and interventions to improve outcomes.

303 For critical care, there was greater diversity around its use and definition. There was widespread 304 agreement that critical care is the care of critically ill patients including the support of vital organs. However, there were differing uses around the location of the care and the need for specialized resources. Some sources considered critical care to be only the care provided in certain locations, (such as ICUs or critical care units), or to be care that is always highly specialized or resource-intensive. The World Federation of Societies of Intensive and Critical Care Medicine have suggested that critical care is synonymous with intensive care and is, " $a$

310 multidisciplinary and interprofessional specialty dedicated to the comprehensive management of 311 patients having, or at risk of developing, acute, life-threatening organ dysfunction. [Critical 
medRxiv preprint doi: https://doi.org/10.1101/2022.01.09.22268917; this version posted January 10, 2022. The copyright holder for this preprint (which was not certified by peer review) is the author/funder, who has granted medRxiv a license to display the preprint in perpetuity. It is made available under a CC-BY-NC-ND 4.0 International license.

312 care] uses an array of technologies that provide support of failing organ systems, particularly 313 the lungs, cardiovascular system, and kidneys."(18) In contrast, other sources used critical 314 care to be inclusive of any care for patients with critical illness, irrespective of location or 315 resources. The Joint Faculty of Intensive Care Medicine of Ireland state that critical care units 316 are those that, "provide life sustaining treatment for critically ill patients with acute organ 317 dysfunction due to potentially reversible disease",(23) and in Belgium, critical care beds have 318 been defined as any beds "for patients with one or more organ functions compromised"(24) 319 Hirshon et al strike a balance between these two contrasting views, "[Critical care is] the 320 specialized care of patients whose conditions are life-threatening and who require comprehensive care and constant monitoring, usually in intensive care units." (25)

322

323

324

325

326

327

328

329

330

331

332

333

334

335

336

337

338

339

340

Our proposed definition of, "the identification, monitoring and treatment of patients with critical illness through the initial and sustained support of vital organ functions", aims to be inclusive. Critical care may include the use of specialized resources but it is not a requirement. We see this as a strength in the definition, as it maintains a patient-centred rather than setting-dependent focus. Critical care when defined in this way can be provided anywhere and does not have to be resource-intensive - it includes both high-resource care in ICUs and lower resource care in other settings. Indeed, critical care can even be provided in general wards, in small health facilities, in the community or in ambulances. High-resource intensive care may not be possible in lowresource settings, but such settings care for many critically ill patients who require critical care $(4,26,27)$. The definition focuses on supporting vital organ functions, emphasising that critical care's primary focus is treating the critical condition of the patient rather than definitive care for the underlying condition(28,29). Critical care, as we have defined it, can be seen as a system of care of patients with critical illness throughout the course of their illness, from the time of their first contact with healthcare through to resolution of the critical illness or death. Critical care is part of the wider concept of acute care which also includes prehospital care, emergency care, trauma and surgery care, as well as in-patient care in medical, surgical, pediatric, obstetric and other wards(29).

\section{Strengths and Limitations}


341 To our knowledge, this is the first study attempting to describe the uses and definitions of the

342 concepts critical illness and critical care, and to identify the defining attributes leading to

343 proposed definitions of the concepts. A strength is the use of both a scoping review of the

344 literature and the inclusion of over one hundred clinical experts as sources. The findings of the

345 analysis should be seen as a first step and we recognise that the use of concepts is fluid and

346 changes over time (6). We were limited to including literature in English and to published studies

347 and guidelines and we may have missed relevant publications in other languages or in other grey

348 literature. Our sample of experts was purposively selected and had global representation but was

349 not perfectly symmetrical to continents, specialty, cadre or gender and we are likely to have

350 missed experts who could have provided valuable contributions. We acknowledge that the

351 proposed definitions may not be universally accepted, and we hope our analysis and findings

352 move the conversation forwards, providing input about how to communicate and collaborate

353 around these vitally important concepts, and ultimately how to improve the care and outcomes

354 for critically ill patients.

355

356

\section{Conclusion}

357 The concepts critical illness and critical care lack consensus definitions and have varied uses.

358 Through concept analysis of the uses in the literature and among experts we propose the 359 definitions: "Critical illness is a state of ill health with vital organ dysfunction, a high risk of 360 imminent death if care is not provided and the potential for reversibility" and "Critical care is 361 the identification, monitoring and treatment of patients with critical illness through the initial and sustained support of vital organ functions."

Acknowledgements: We thank all the experts who participated in the study.

Author Contributions: TB \& OS designed the study. RKK, TT, HM and TB collected the data. All the authors contributed to analysing the data. RKK and TB wrote the first draft of the manuscript. All authors critically reviewed the manuscript and approved the final version. The 
corresponding author attests that all listed authors meet authorship criteria and that no others meeting the criteria have been omitted.

Funding: This research received no specific grant from any funding agency in the public, commercial or not-for-profit sectors

Disclaimer: We confirm the independence of researchers and that all authors in study can take responsibility for the integrity of the data and the accuracy of the data analysis.

Competing Interests: None Declared

Patient Consent for Publication: Not required

Ethics Approval: The Research Ethics Committee of the London School of Hygiene and Tropical Medicine approved the study (Reference number 22661).

Provenance and Peer Review: Not commissioned, externally reviewed

Data Availability Statement: The study data are available from the corresponding author on reasonable request

Supplementary Files: Supplementary Tables 1 and 2

\section{References}

1. Adhikari NK, Fowler RA, Bhagwanjee S, Rubenfeld GD. Critical care and the global burden of critical illness in adults. The Lancet. 2010 Oct;376(9749).

2. Vukoja M, Riviello ED, Schultz MJ. Critical care outcomes in resource-limited settings. Current Opinion in Critical Care. 2018 Oct;24(5):421-7.

3. Biccard BM, Gopalan PD, Miller M, Michell WL, Thomson D, Ademuyiwa A, et al. Patient care and clinical outcomes for patients with COVID-19 infection admitted to African high-care or intensive care units (ACCCOS): a multicentre, prospective, observational cohort study. The Lancet. 2021 May;397(10288):1885-94.

4. Murthy S, Leligdowicz A, Adhikari NKJ. Intensive Care Unit Capacity in Low-Income Countries: A Systematic Review. PLOS ONE. 2015 Jan 24;10(1):e0116949.

5. Arabi YM, Azoulay E, Al-Dorzi HM, Phua J, Salluh J, Binnie A, et al. How the COVID-19 pandemic will change the future of critical care. Intensive Care Medicine. 2021 Mar 22;47(3):282-91. 
6. Walker LO, Avant KC. Strategies for Theory Construction in Nursing. 5th Edition. Pearson; 2011.

399

400

401

402

403

404

405

406

407

408

409

410

411

412

413

414

415

416

417

418

419

420

421

422

423

424

425

426

427

428

429

430

431

432

433

7. Xyrichis A, Ream E. Teamwork: A concept analysis. Journal of Advanced Nursing. 2008 Jan;61(2):232-41.

8. Allvin R, Berg K, Idvall E, Nilsson U. Postoperative recovery: a concept analysis. Journal of Advanced Nursing. 2007 Mar;57(5).

9. Rebmann T. Defining bioterrorism preparedness for nurses: concept analysis. Journal of Advanced Nursing. 2006 Jun;54(5).

10. Arksey H, O'Malley L. Scoping studies: towards a methodological framework. International Journal of Social Research Methodology. 2005 Feb;8(1).

11. Ouzzani M, Hammady H, Fedorowicz Z, Elmagarmid A. Rayyan-a web and mobile app for systematic reviews. Systematic Reviews. 2016 Dec 5;5(1).

12. Erlingsson C, Brysiewicz P. A hands-on guide to doing content analysis. African Journal of Emergency Medicine. 2017 Sep;7(3).

13. Schell CO, Castegren M, Lugazia E, Blixt J, Mulungu M, Konrad D, et al. Severely deranged vital signs as triggers for acute treatment modifications on an intensive care unit in a low-income country. BMC Research Notes. 2015 Dec 25;8(1).

14. Seymour CW, Liu VX, Iwashyna TJ, Brunkhorst FM, Rea TD, Scherag A, et al. Assessment of Clinical Criteria for Sepsis. JAMA. 2016 Feb 23;315(8).

15. Smith GB, Redfern OC, Pimentel MA, Gerry S, Collins GS, Malycha J, et al. The National Early Warning Score 2 (NEWS2). Clinical Medicine. 2019 May 15;19(3).

16. Knaus WA DEWDZJ. APACHE II: a severity of disease classification system. Critical Care Medicine.

17. Moreno RP, Metnitz PGH, Almeida E, Jordan B, Bauer P, Campos RA, et al. SAPS 3 - From evaluation of the patient to evaluation of the intensive care unit. Part 2: Development of a prognostic model for hospital mortality at ICU admission. Intensive Care Medicine. 2005;31(10):1345-55.

18. Marshall JC, Bosco L, Adhikari NK, Connolly B, Diaz J v., Dorman T, et al. What is an intensive care unit? A report of the task force of the World Federation of Societies of Intensive and Critical Care Medicine. Journal of Critical Care. 2017 Feb;37:270-6.

19. Schell CO, Khalid K, Wharton-Smith A, Oliwa J, Sawe HR, Roy N, et al. Essential Emergency and Critical Care: a consensus among global clinical experts. BMJ Global Health. 2021 Sep 21;6(9).

20. Maharaj R, Raffaele I, Wendon J. Rapid response systems: a systematic review and meta-analysis. 2015;

21. Chandrashekar M, Shivaraj BM, Krishna VP. A study on prognostic value of serum cortisol in determining the outcome in the critically ill patients. Journal of Evolution of Medical and Dental Sciences. 2015 Jul 17;4(58). 
434 22. Painter JR. Critical Care in the Surgical Global Period. Chest. 2013 Mar;143(3).

435 23. Joint Faculty of Intensive Care Medicine of Ireland. National Standards for Adult Critical Care Services 2011. 2011.

437 24. Wunsch H, Angus DC, Harrison DA, Collange O, Fowler R, Hoste EAJ, et al. Variation in critical care services across North America and Western Europe*. Critical Care Medicine. 2008 Oct;36(10):2787-e8.

25. Hirshon JM, Risko N, Calvello EJ, Stewart de Ramirez S, Narayan M, Theodosis C, et al. Health systems and services: the role of acute care. Bulletin of the World Health Organization. 2013 May $1 ; 91(5): 386-8$.

443

26. Prin $\mathrm{M}$, Wunsch $\mathrm{H}$. International comparisons of intensive care. Current Opinion in Critical Care. 2012 Dec;18(6):700-6.

27. Manda-Taylor L, Mndolo S, Baker T. Critical care in Malawi: The ethics of beneficence and justice. Malawi Medical Journal. 2017 Nov 24;29(3):268.

28. Schell CO, Gerdin Wärnberg M, Hvarfner A, Höög A, Baker U, Castegren M, et al. The global need for essential emergency and critical care. Vol. 22, Critical Care. BioMed Central Ltd.; 2018.

29. Baker T, Schell CO, Petersen DB, Sawe H, Khalid K, Mndolo S, et al. Essential care of critical illness must not be forgotten in the COVID-19 pandemic. The Lancet. 2020 Apr;395(10232). 